University of Nebraska - Lincoln

DigitalCommons@University of Nebraska - Lincoln

To Improve the Academy

Professional and Organizational Development Network in Higher Education

1994

The Value of Classroom Humor

Richard J. Nichols

Beverley T. Amick

Madelyn Healy

Follow this and additional works at: https://digitalcommons.unl.edu/podimproveacad

Part of the Higher Education Administration Commons

Nichols, Richard J.; Amick, Beverley T.; and Healy, Madelyn, "The Value of Classroom Humor" (1994). To Improve the Academy. 316.

https://digitalcommons.unl.edu/podimproveacad/316

This Article is brought to you for free and open access by the Professional and Organizational Development Network in Higher Education at DigitalCommons@University of Nebraska - Lincoln. It has been accepted for inclusion in To Improve the Academy by an authorized administrator of DigitalCommons@University of Nebraska - Lincoln. 


\section{The Value of Classroom Humor}

\section{Richard J. Nichols}

Beverley T. Amick

\section{Madelyn Healy}

Kean College of New Jersey

This article provides a model workshop which faculty developers can present to make the case for faculty to use humor as an aid to student learning. The uses of humor, the potential for it to be harmful, the benefits of humor when effectively used, and guidelines for classroom use are addressed.

\section{Introduction}

In the midst of challenging times, what the world needs now is laughter, sweet laughter. Humor and creativity are gifts we can give ourselves to survive and thrive in the 90 s. Humor and creativity play a vital role in living, learning, working, and being healthy.

The preceding quotation, taken from the announcement for the 9th Annual International Conference on the Positive Power of Humor and Creativity (1994), states the position on humor held by the writers. We especially accept the proposition that humor plays a vital role in learning. This proposition is supported by research on teachers cited by Dean (1993). Dean comments that a study by Abramis (1991) found that teachers who used humor were rated more favorably by their students than were teachers who did not use humor. In this brief account we will first make the case for the use of humor as an aid to 
learning, and then present a design for a workshop on humor in the classroom.

\section{Humor as an Aid to Learning}

We begin the case by citing four beliefs we hold regarding humor and learning. Adapted from Kelly (1988), these beliefs are:

1. Humor can enhance and advance the educational process.

2. ...learning and laughter are compatible.

3. Used properly, humor improves the learning environment and fosters implementation of positive attitudes.

4. Humor, properly used, can be a very useful tool, technique, strategy, and attitude to make learning more enjoyable and worthwhile.

Key to these beliefs is the phrase, "properly used." We would be among the first to acknowledge that some humor may be hurtful or harmful to others, and that such humor has no place in the college classroom. Humor which makes fun of others, which involves put downs, or which stresses the superiority of ourselves should not be part of one's teaching repertoire. Rather, the type of humor which may be used most effectively in the college classroom is that which takes advantage of unexpected connections, i.e., humor based in incongruities.

Cornett (1986) has suggested that two theories underlie much of humor: 1) superiority, which suggests humans derive pleasure from seeing themselves as better off than others, and which we would argue is inappropriate for the classroom; and 2) incongruity, which involves unexpected connections, and which we would argue has many benefits for learning.

A cartoon which appears in The Student Body: Great Cartoons from the Kappan, edited by Bucheri, Hampton, and Voelker (1991) illustrates both theories at play. The cartoon by Dave Carpenter shows a professor speaking with a student about the student's results on a history test (the student's test paper shows an F) and remarking: "They say that history repeats itself-and in your case, it might be next semester." If a professor were to actually say that to a student, particularly if it were done in front of others, the superiority theory 
involving a put down would be demonstrated, and while the situation depicted might be humorous to some, the student involved would be most unlikely to find it funny. However, given the audience for whom the cartoon is intended, the cartoon makes good use of incongruity. The situation itself may be seen as incongruous in that no well-meaning professor would do this, although many may have felt like it at times. In addition, the play on the phrase "history repeats itself" involves incongruity through unexpected connections and requires some use of cognitive skill. This leads us to the definition of humor which we find most useful. The definition is proposed by Cornett (1986), who has written:

Today definitions of humor focus mainly on cognitive aspects of what makes us laugh (language play and unlikely visual and auditory images). Yet remaining with us is the idea of humor as something that is ludicrous, incongruous, abnormal, and out-of-the ordinary. (p. 19)

This definition, with its emphasis on cognitive aspects, provides a particularly appropriate basis for making the case that humor can be an aid to learning. Humor which emphasizes cognitive aspects can have a number of positive effects when used in the learning environment. Westcott (1988) suggests that, among other things, humor can support effective communication, promote creative problem solving, and facilitate conflict management. If it is to have such positive effects, however, those electing to use humor in their classes will wish to consider Westcott's guidelines which include: 1) starting with one's self; 2) taking one's teaching seriously but one's self lightly; 3) being an observer, aware that one is surrounded by humor; 4) using humor as a support for competence rather than as a means for masking a lack of competence; and 5) using humor with sensitivity and care so that it is likely to be appreciated.

Humor, when used in this way, can have many benefits - particularly in one's relations with students. Dean (1993) notes that humor enlivens one's message and helps students to relax and pay attention. According to Dean this results in the following positive effects:

1. You show [students] that you are not afraid to let your guard down.

2. You convey that you are confident about their reactions to you.

3. You demonstrate that you trust them to value your spontaneity. 
4. You reduce the anxiety so that [students] can better deal with the problems they are facing.

5. You help them to gain perspective on their problems and to see those problems in a broader context. (p. 214)

Given these potential benefits of humor, one wonders why instructors don't seem to use it more often, or don't seem to use it particularly well. No doubt there are many possible explanations as to why this is so, but some that appeal to us have been suggested by Paulson (1989). First, he notes that most of us have become far too serious, and that people don't seem to have nearly as much fun as they once did. In support of this explanation, he cites the fact that U.S. workers consume over 15 tons of aspirin a day. Secondly, he notes that many of us have lost touch with the importance of fun in the workplace. He writes:

We move steadily through life with flat expressions on our faces. Take a minute and list [your colleagues] that look like they are in pain most of the day. Before you laugh too hard, think if others might put you on their list. It is dangerous to confuse professionalism with seriousness. You can take your [teaching] and your world seriously, and still take yourself lightly. (p. 1)

Perhaps the most cogent explanation for the failure of instructors to constructively use humor, however, is that it involves taking some risks. As Paulson comments, not all humor works. It can detract from serious discussion; it can be used to deflect valid criticism; it can lead to being criticized for "never taking anything seriously."

Obviously, these are things to be avoided, and many avoid them by never using humor. But in doing so, they also lose the benefits that humor can bring to the classroom. The key, in Paulson's words, is "balance." In an effort to address the issue of balance, we have designed a workshop which we believe to be useful in helping faculty to realize the potential value of humor while also developing their own potential for using humor in their classrooms.

\section{A Workshop on Humor in the Classroom}

The workshop we have employed to work with faculty on the use of humor is focused on three purposes, identified in a handbook 
distributed to participants (see Appendix B). These are: 1) to demonstrate the benefits of the proper use of humor in the college classroom; 2) to suggest the consequences of the improper use of humor in the classroom; and 3) to offer some general guides for the use of cases in teaching.

Designed to actively involve the participants, the workshop can be satisfactorily conducted within a $21 / 2$ hour session. Although we have done it in less time by cutting or reducing some of the activities, it is better done in the longer time frame.

The workshop is structured for maximum participant involvement. (The workshop outline is in Appendix A.) As the people enter the workshop, they are given a copy of the handbook prepared by the writers (Appendix B). They are instructed to complete page 1, Check Your Sense of Humor. The checking of their sense of humor immediately focuses them on the topic. The handbook provides basic information and eliminates note taking. The workshop formally begins with a mini-lecture on who the leaders are, the objectives, and a statement of beliefs about humor.

Following this, the participants are placed in small groups, given a cartoon, and asked to discuss it using guide questions in the handbook. Groups share their cartoons and their analyses of why they are funny. The total group discussion which follows focuses on the place of humor in the classroom and what was learned about ourselves. Participants enjoy the discussion and frequently ask for cartoon copies.

The next activity is a mini-lecture in which theoretical information such as a definition of humor, the humor process, and benefits of humor are presented. At this point a case study on the uses of humor is distributed for silent reading (Appendix C). The purpose of the case study is to stimulate reflection and discussion about the appropriate use of humor in teaching. The participants return to the small groups and use the guide questions to discuss the case study. This is followed by whole-group discussion which focuses on the effective use of humor and how to advise faculty about its use.

The next activity, again done in small groups, involves sharing the answers to the questions on page 1 of the handbook. They are directed to share the responses to Item 2, "A funny thing that happened to me 
in the classroom was " Laughter comes from the groups and they are eager to share their incidents with the total group. Discussion is then held on the potential of these incidents to serve as a basis for case studies. The session closes with a presentation of guidelines for effective use of humor. Frequently, participants are reluctant to leave and often remain to discuss the issues with each other and/or with the workshop leaders.

\section{Summary and Conclusions}

Our experience with this workshop has been very satisfying, and the feedback received has been quite positive. For example, the last time the workshop was conducted, results on the evaluation form revealed that 16 of the 17 participants $(94.1 \%)$ agreed or strongly agreed (i.e., rated 4 or 5) with the statement, "This session had fresh, significant perspectives of value"; while all 17 or $100.0 \%$ agreed or strongly agreed with the statement, "The handouts/ supplementary materials were a valuable addition to the session" and that "Considering everything, this presentation was rewarding and worthwhile." Written comments for the session included: "Great group!" "Excellent!" "The discussion was very stimulating. I learned and enjoyed." Positive reactions were also evidenced at a prior workshop by a suggestion that we "Take this show on the road."

These positive reactions are due in part, we believe, to the fact that this is not a topic that has been very seriously examined for its potential use as an aid to learning, and it is, therefore, a new area of exploration for many.

We also believe it is successful because we do not emphasize being funny (none of the writers is a particularly noteworthy comedian), but rather, on having fun. In the words of Lawrence J. Peter and Bill Dana, as cited by Paulson (1989), we ask our participants to:

Realize that a sense of humor is deeper than laughter, more satisfying than comedy and delivers more rewards than merely being entertaining. A sense of humor sees the fun in everyday experiences. It is more important to have fun than it is to be funny. 


\section{References}

Abramis, D. (1991, March 19). There is nothing wrong with a little fun. The San Diego Union, p. 25.

Bucheri, C., Hampton, T., \& Voelker (Eds). (1991). The student body: Great cartoons from the Kappan. Bloomington, IN: Phi Delta Kappa.

Cornett, C.E. (1986). Learning through laughter: Humor in the classroom. Bloomington, IN: Phi Delta Kappa.

Dean, O. (1993). The effect of humor in human resources development. In J.W. Pfeiffer (Ed.), The 1993 annual: Developing human resources, (pp. 213-219). San Diego: Pfeiffer \& Co.

Kelly, W.E. (1988). Laughter and learning: Humor in the classroom. Portland, ME: J. Weston Walch.

Paulson. T.L. (1989). Making humor work: Take your job seriously and yourself lightly. Los Altos, CA: Crisp Publications, Inc.

The positive power of humor and creativity. (1994), conference catalog. Saratoga Springs, NY: The Humor Project, Inc.

Westcott, J.M. (1988). Humor and the effective work group. In J.W. Pfeiffer (ed.), The 1988 annual: Developing human resources (pp. 139-142). San Diego: University Associates. 


\section{APPENDIX A \\ Outline for Workshop}

\section{Humor in the Classroom}

Topic/Activity

Approximate Time

I. Pre-prep 10 minutes

Upon entering participants are given a handbook prepared by the writers, and asked to take the "exam" on page 1.

II. Introduction 15 minutes

In a brief mini-lecture we indicate:

A. Who we are; what we are not

B. Statement of purposes

Cover page of handbook

C. Statement of beliefs

Page 2 of handbook

III. Humor and cartoons

25 minutes

A. Participants are placed in small groups (3

to 5 persons) and each group receives a copy of a different cartoon (selected by the presenter - see page 12 in handbook for cartoon sources). Groups are asked to discuss their cartoons by addressing the questions on page 3 of the handbook.

B. Each group reports on its cartoon. (Copy of each cartoon is shown on overhead).

C. Whole group discussion then takes place focussing on what we've learned about ourselves and about humor and its place in the classroom based on this activity.

IV. What have we learned about humor? 20 minutes "Piggybacking" on the preceding discussion a minilecture using overheads and pages 4 through 7 of 
the handbook addresses the following:

A definition of humor

Humor's three-step process

Two theories of humor

Benefits of using humor

V. Case study

40 minutes

A. A brief ( 2 pages) case study entitled "The Good, The Bad, and The Ugly," dealing with uses of humor is distributed and participants read it silently. (For a copy of the case study see Appendix C.)

B. The case study is discussed in small groups, using a discussion guide attached to the case study.

C. A whole group discussion of the case study follows.

VI. Sharing incidents for cases

25 minutes

A. In their small groups, individuals are asked to return to the "exam" taken upon entry (see I) and to share their comments, especially on item 2 , "A funny thing that happened to me in the classroom was

B. Each group then selects one incident to be shared with the total group.

C. Incidents are shared and their potential as bases for case studies is discussed.

VII. Closure 15 minutes

A. Guidelines for effective use of humor (page 9 of the handbook)

B. The Common Sense Commandments of humor (page 11 of the handbook)

C. Sources of material (page 12 of handbook) 


\section{APPENDIX B \\ Handbook for Workshop on Humor in the Classroom}

\section{Cover Page}

\section{The Value of Classroom Humor: A Case Study}

\section{A Workshop Designed to:}

1. Demonstrate the benefits of the proper use of humor in the classroom.

2. Suggest the consequences of the improper use of humor in the classroom

3. Offer some general guides on the use of cases in teaching.

* Each page in this handbook was printed in large type and overheads were made of each page. For purposes of this article, the print has been reduced and pages "doubled up."

\section{Page 1}

\section{Check Your Sense of Humor}

1. On a 1 to 10 scale, my sense of humor is . (Note 10 as excellent and 1 as nonexistent).

2. A funny thing that happened to me in the classroom was

3. I laughed until I cried when

4. My laugh could be described as

5. I hate it when someone laughs when

Adapted from Cornett, 1986. 


\section{Page 2}

Our Beliefs Re: Humor in the Classroom

1. "Humor can enhance and advance the educational process."

2. "...learning and laughter are compatible."

3. "Used properly, humor improves the learning environment and fosters implementation of positive attitudes."

4. "Humor...properly used, can be a very useful tool, technique, strategy, and attitude to make learning more enjoyable and worthwhile."

From Kelly, 1988.

\section{Page 3}

Discussion Questions for Cartoon

1. Do you find this humorous?

2. Why or why not?

3. What must you "bring" to the cartoon to see the humor?

4. Other thoughts or reactions.

\section{Page 4}

\section{Humor Defined}

"Today definitions of humor focus mainly on cognitive aspects of what makes us laugh (language play and unlikely visual and auditory images). Yet remaining with us is the idea of humor as something that is ludicrous, incongruous, abnormal, and out-of-the-ordinary."

From Cornett, 1986.

\section{Page 5}

\section{Humor's Three-Step Process}

1. Arousal

2. Problem Solving

3. Resolution

From Cornett, 1986. 


\section{Page 6}

\section{Two Theories of Humor}

1. Superiority -Humans derive pleasure from seeing themselves as better off than others.

2. Incongruity -Unexpected connections.

From Cornett, 1986.

\section{Page 7}

\section{Benefits of Using Humor}

"If your message is worthwhile but boring, the chances are that it will not be heard, understood, and remembered. Humor enlivens your message and helps [students] to relax and pay attention."

1. You show [students] that you are not afraid to let your guard down.

2. You convey that you are confident about their reactions to you.

3. You demonstrate that you trust them to value your spontaneity.

4. You reduce anxiety so the [students] can better deal with the problems they are facing.

5. You help them to gain perspective on their problems and to see those problems in a broader context.

Adapted from Dean, 1993.

\section{Page 8}

\section{Some Considerations When Preparing or Using a Case}

1. Necessary background information

2. Context - A real and recognizable situation

3. A dilemma of some complexity

4. Requires reflective thought

Adapted from Materials provided by Case Study Workshops. 


\section{Page 9}

\section{Guidelines for Effective Use of Humor}

1. Start with yourself....

2. Be able to take your work seriously but yourself lightly...probably the best source of humor is personal experience.

3. Be an observer. Be aware that you are surrounded by humor and notice that humor.

4. Think of humor as being of two kinds — public and private....

5. Use humor as a support for competence rather than as a means of masking a lack of competence.

6. Use humor with sensitivity and care so that it is likely to be appreciated.

- Make fun of yourself - not others

- Laugh with people - not at them

- Avoid ethnic put downs

- Avoid sexist put downs

Adapted from Westcott, 1988.

\section{Page 10}

\section{The Last Word}

Plato once said, "Do not train students to learn by force and harshness; but direct them to it by what amuses their minds so that you may be the better able to discover with accuracy the peculiar bent of the genius of each."

$$
\text { From Kelly, } 1988 .
$$

\section{Page 11}

\section{The (Common) Sense Commandments...of Humor}

1. It is important to take your job seriously...and yourself lightly. There is a big difference between being "serious" and being "solemn." 
2. Laughter is the shortest distance between two people. (Victor Borge)

3. There is a direct relationship between the funny line and the bottom line.

4. You can't help getting older...but you can help getting old. (George Burns)

5. When humor goes, there goes civilization. (Erma Bombeck)

6. Humor is our greatest national resource which must be preserved at all costs. (James Thurber)

7. Love may make the world go 'round, but laughter keeps us from getting dizzy. (Donald Zochert)

8. Humor is a proof of faith. (Charles M. Schulz)

9. You grow up the day you have your first real laugh - at yourself. (Ethel Barrymore)

10. Misery loves company...but laughter loves it even more! Ye shall go forth and multiply mirth and give birth to creativity.

From Mirth Certificate. The Humor Project, Inc.

Saratoga Springs, NY

\section{Page 12}

\section{Handbook Sources of Material}

\section{Resources}

Cornett, C.E. (1986). Learning through laughter: Humor in the classroom. Bloomington, IN: Phi Delta Kappa.

Dean, O. (1993). The effect of humor in human resources development. In J.W. Pfeiffer (ed.), The 1993 annual: Developing human resources (pp. 213-219). San Diego: Pfeiffer \& Co.

Kelly, W.E. (1988). Laughter and learning: Humor in the classroom. Portland, ME: J. Weston Walch.

Paulson. T.L. (1989). Making humor work: Take your job seriously and yourself lightly. Los Altos, CA: Crisp Publications, Inc.

Westcott, J.M. (1988). Humor and the effective work group. In J.W. Pfeiffer (ed.), The 1988 annual: Developing human resources (pp. 139-142). San Diego: University Associates. 


\section{Cartoon Sources}

Bucheri, C., Hampton, T., \& Voelker (eds). (1991). The student body: Great cartoons from the Kappan. Bloomington, IN: Phi Delta Kappa.

Herzog, K. (ed.) (1985). Recess time: The best cartoons from the Kappan. Bloomington, IN: Phi Delta Kappa.

Herzog, K. \& Miller, M.P. (eds.). (1985). Scholarship: More great cartoons from the Kappan. Bloomington, IN: Phi Delta Kappa.

\section{Annual Conference}

The Humor Project, Inc., 100 Spring St., Saratoga Springs, NY 12866. Purchasers from this Project are awarded a MIRTH CERTIFICATE which lists "The Common Sense Commandments...of Humor." 


\section{APPENDIX C Case Study}

\section{The Good, the Bad and the Ugly}

(Productive, nonproductive, and counterproductive uses of humor)

Professor Yenolab, an experienced teacher (seven years in the English Department, two sections of Freshman composition, one section on the modern novel, and a senior seminar) has come to a mentor for advice and the following dialogue ensues:

Professor: I just finished reviewing my student evaluations for this semester and they were "all over the lot," ranging from "Best class I've had" to "A so-so class" to "This was a terrible experience," with, I'm sad to say, more in the so-so and terrible categories than I've ever had before.

Mentor: Did this occur more in one particular section?

Professor: No, that's what bothers me. It was pretty well across all sections with perhaps a few more negative comments from the freshman composition classes.

Mentor: Uh-huh.

Professor: I've always thought of myself as a pretty good teacher, reasonably well liked by my students. I work hard to make my classes lively and fun, and I just don't understand what happened this semester.

Mentor: Tell me what you do to make your classes lively and fun.

Professor: Well, for one thing I try to use humor a lot. I write humorous comments on students' papers, I insert jokes in my lectures, I pick up on incidents that are humorous, I use humorous examples to make a point-I don't know-I think learning should be fun and I try to make it so.

Mentor: Uh-huh. Can you tell me more about your use of humor?

Professor: Sure. Sometimes I plan for it-building it into my presentation. Other times it just happens-something comes up in class that I think is funny, and I build on it. 
Mentor: Can you give me some examples?

Professor: Well, O.K. When I first meet with a class I like to try to set a tone that lets them know I'm in charge but also lets them know that I'm easy going and approachable, so I might kiddingly say to the class, "You're no doubt familiar with the saying, 'A little learning is a dangerous thing'-well you needn't worry-you're all perfectly safe."

Or when I get ready to hand back an exam I have a cartoon I like to show that I think relieves some of the anxiety. The cartoon shows a professor with a stack of papers in hand standing before a class saying, "Before I hand back your tests, I'd just like to tell you how nice it is to know that in today's atmosphere of high-pressured competition, there are still students who don't give a damn about grades."

Mentor: Umm. How do the students usually respond to these?

Professor: Some laugh, but I don't seem to get the response I used to. I think kids are too serious these days.

Mentor: Yes, well...These would seem to be examples of planned use of humor. Can you give me an example of something spontaneous-a situation that you built on as you said earlier?

Professor: Let me think. Oh yeah, here's one. I had the class working in small groups - each group responding to a set of questions on homonyms or homophones. One group asked what I was looking for in one of my questions involving the use of "manner" and "manor." I replied, "beats me," to which one of the group responded, "Wouldn't I like to." Knowing the student well and that the comment was meant jokingly I laughed and it led to a whole class discussion of the use of words with more than one meaning, use of context and related topics.

Mentor: Umm, yes. Well, let's see-where are we now?

\section{Discussion Guide}

In your group discuss your reactions to this dialogue and where you think "they are now." In your discussion you may wish to consider some of the following:

1. How would you categorize the humor in each instance (superiority, incongruity, a combination)? Could the professor's use of humor have been a factor in the student evaluations? If so, in what way? 
2. What were the probable consequences of the use of humor in each of the instances cited. Why do you think so?

3. How would you advise Professor Yenolab? 